\title{
NUEVA LECTURA DE UNA INSCRIPCIÓN VOTIVA BILINGÜE DE LAS TERMAS DE GERMÍSARA (DACIA SUPERIOR)
}

\author{
Antonio Melero Bellido - Ricardo Hernández Pérez \\ Universidad de Valencia \\ antonio.melero@uv.es - ricardo.hernandez@uv.es
}

\begin{abstract}
RESUMEN
Nueva edición y comentario filológico de una larga y compleja inscripción votiva de la época de Cómodo que consta de un poema en latín (redactado en hexámetros dactílicos) seguido, a modo de complemento y amplificación, de un texto griego en prosa pero con cierto color poético. La inscripción está dedicada a la Ninfa de un santuario termal, mencionada con lo que parece ser un nombre o epíteto local, y consiste tanto en la conmemoración del cumplimiento de un voto determinado como en la narración de las fiestas anuales que la unidad mili$\operatorname{tar}$ (numerus) comandada por el dedicante celebraba, mediante ofrendas votivas y sacrificios, en honor tanto de la Ninfa del lugar como de Asclepio, Panacea, Ártemis e Hypnos. Se narra también, en el texto griego, una sanatio y las ofrendas correspondientes en acción de gracias. El uso del griego en este epígrafe parece que deba explicarse por una razón de prestigio cultural.

PALABRAS CLAVE: epigrafía latina, epigrafía griega, epigrafía votiva, carmina Latina epigraphica, bilingüismo en el Imperio Romano, Ninfas, Asclepio, Panacea, Ártemis, Hypnos, sanatio, termas de Germisara, Dacia, praepositus numeri, numerus peditum singularium Britannicianorum.
\end{abstract}

\section{A NEW READING OF A BILINGUAL VOTIVE INSCRIPTION FROM GERMISARA THERMAL BATHS (DACIA SUPERIOR)}

\section{ABSTRACT}

New edition and philological commentary of a long and complex votive inscription from the time of Commodus consisting of a poem in Latin (written in dactylic hexameters) followed, as a complement and amplification, by a Greek text in prose with a certain poetic color. The inscription is dedicated to the Nymph of a thermal sanctuary, mentioned by what appears to be a name or local epithet, and consists both of the commemoration of the fulfillment of a vow and in the narration of the annual festivals that the military unit (numerus) commanded by the dedicator celebrated, through votive offerings and sacrifices, both in honor of the Nymph of the place and of Asclepius, Panacea, Artemis and Hypnos. It is also narrated, in the Greek text, a sanatio and the corresponding offerings of thanksgiving. The use of Greek in this epigraph seems to have to be explained for a reason of cultural prestige.

KEYwORDS: Latin epigraphy, Greek epigraphy, votive epigraphy, carmina Latina epigraphica, bilingualism in the Roman Empire, Nymphs, Asclepius, Panacea, Artemis, Hypnos, sanatio, Germisara baths, Dacia, praepositus numeri, numerus peditum singularium Britannicianorum. 


\section{INTRODUCCIÓN}

Nuestra aportación al merecido homenaje rendido mediante este volumen al profesor Ángel Martínez consiste, sobre todo, en una nueva propuesta de lectura de un texto epigráfico que, tal como fue editado por Ioan Piso y pese a las correcciones intentadas por otros epigrafistas (véase más abajo la bibliografía de la inscripción), necesita ciertas mejoras. Nuestra lectura se basa en el examen de la excelente fotografía publicada por Piso (a la que puede accederse cómodamente mediante la base de datos EDCS: registro no 71200587) y en el debido análisis de los aspectos lingüísticos, métricos, estilísticos, epigráficos, literarios y de realia. Esperamos que nuestro trabajo sea una contribución previa a la fijación definitiva del texto mediante una nueva autopsia, que nosotros no hemos podido hacer.

Se trata de una inscripción votiva bilingüe (en latín y en griego) grabada sobre una estela de caliza $(160 \times 60 \times 15)$. Fue hallada en las excavaciones realizadas durante 1986 y 1987 en las antiguas termas dacorromanas de Geoagiu (Rumanía), situadas a $5 \mathrm{~km}$ al norte (cf. infra comm. ad v. 2) del fuerte romano de Germisara (Dacia superior), localizado en el área de Cigmău (dependiente del municipio de Geoagiu) y que perteneció, según parece, al territorio de la colonia Vlpia Traiana Sarmizegetusa (cf. Patsch, RE VII.1, 1263, 58 ss.; L. Marinescu, PECS 350; Rusu - Pescaru, 1993). Se conserva en el Museo de la civilización dacia y romana (Deva). Datación: 183/185 d. C. (cf. infra ad 1. 29 s.).

\section{TEXTO Y TRADUCCIÓN}

Piso, 2015: 47-68, con fotografías y dibujo (reseña en $A E 2015$, 1186, con análisis y propuestas de lectura de N. Boëls, S. Follet y B. Puech); Dana, 2015; Petolescu, 2017: 197-201, no 1909.

Sunt Getici fontes diuina Nymfa creati, cui formonsus ager uicinus Germisarae est, cui miles Brittannicus sollem ${ }^{\wedge}$ nia $\mathrm{a}^{\wedge}$ nnua ducit ex uoto referens soluitque uota priora temporis excessi et rusum suscipit ipse, cui cristatus apex procumbit uortice summo. hinc undas $\mathrm{i}^{\wedge} \mathrm{ntrạ}[\mathrm{t}]$ ḅo[n] ạ f̣luentes $\mathrm{V++++}$ RE illinc, unde et pumiceu[s fons et liq] uor inde salutis exuṛ[git] fiuntq̣[ue ---]++ quantus [---]

10 VIRṬ[---]um[qu]e domum[q]ue $[---]$ in annọ $[\mathrm{s}]$ [--- ] quẹmque uoueraț $[\mathrm{h}] \operatorname{ortu}^{\wedge} \mathrm{m}$ [--- ]us praepositus hunc (?) fero $+++\mathrm{ON}+$ [---]re cingeris uite comati

15 [dul] ç̣ dignata dono circumdata uuis. te precor, Odrysia, donum ilarạta recondas.

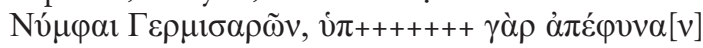

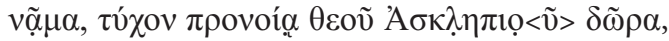




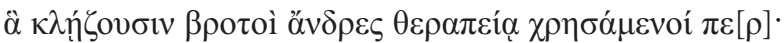

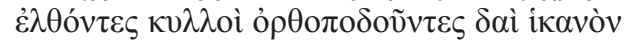

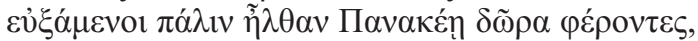

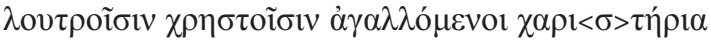

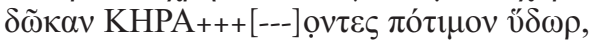

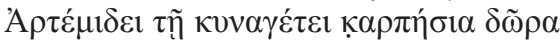

25

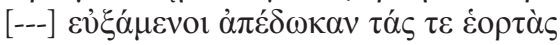

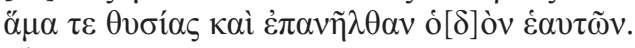

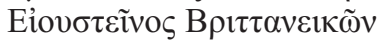

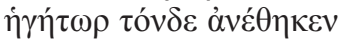

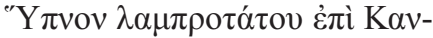

30

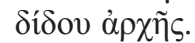

C. Sentius Iustinus (centurio) l(e)g(ionis)

V Mac(edonicae) agens per terr(itorium) Lucanum.

1 Nymfa pro Nympha, Nympha scripsit Piso (inde ceteri). 4 referens perspeximus, efferens haud recte Piso (inde ceteri). 5 rusum pro rursum. 7 sic legendum putamus, undas miles (?) conuenas uidere solens haud recte Piso (inde ceteri). 8 supplevimus collato Mart. 4, 57, 2, et pu[--- ae?]quor Piso (inde Dana), et pu+++[---li?]quor AE, et pumice [aquae ae]quor Petolescu contra metrum. 9 sic legendum putamus, excipiunt [---] Piso (inde ceteri). 10 incertum utrum uirt[us ---] (uirtus Piso, inde ceteri) vel uirt [ut---] an uir t[---] legendum sit; litteras post lacunam servatas omisit Piso (inde ceteri). 11 litteras in fine versus post lacunam servatas omisit Piso (inde ceteri); fortasse supplendum [--- multos vel longos ---]. 12 sic legendum putamus, [---]que nouerat portam Piso (inde ceteri). 13 sic legendum putamus (Iustin] us fortasse supplendum, cf. v. 27 et 31), [---] praepositus hunc tibi [---] Piso (inde ceteri). 14 prope]re fortasse supplendum, [---]re cingeris dubitanter scripsit Piso (inde Dana et Petolescu), [---] recingeris vix recte AE. 15 [dul]ci dignata perspeximus et supplevimus, [---]o nata haud recte Piso (inde ceteri). 16 Odrysta Piso, Odrysia dubitanter AE, o Drysta Petolescu; ilarata (pro hilarata) perspeximus, terrena dubitanter Piso

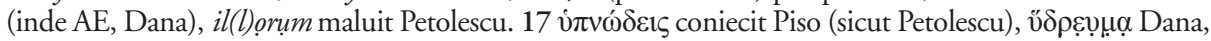
vं $\pi[\varepsilon \rho \varphi v \tilde{\omega}$ ?] AE; $\dot{\alpha} \pi \dot{\varepsilon} \varphi v v \alpha[v]$ haud recte intransitive usurpatum putavit Piso, qui vertit "sind von Natur",

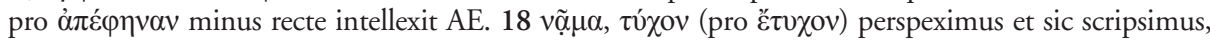

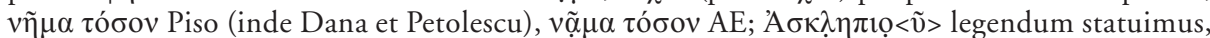

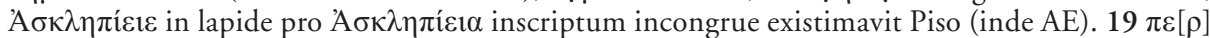
supplevit Piso (inde ceteri). $20 \delta \alpha \grave{\text { pro } \delta \dot{\varepsilon} \text {, ut recte intellexit AE, pro } \delta \eta ́ ~ h a u d ~ r e c t e ~ P i s o ; ~ i ́ \kappa a v o ̀ v ~}$

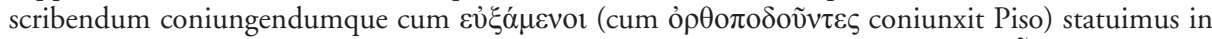

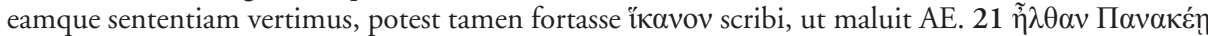

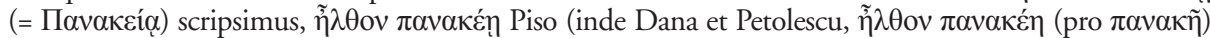

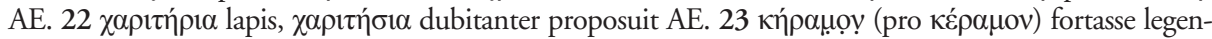

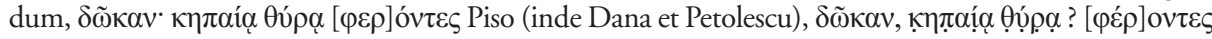

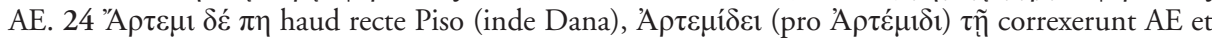

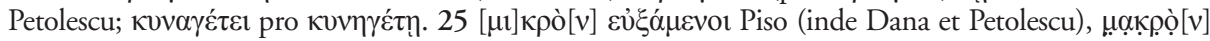

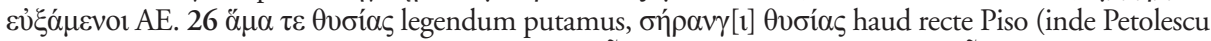

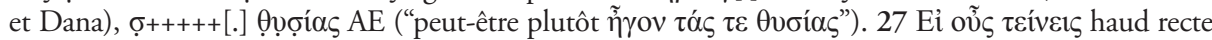

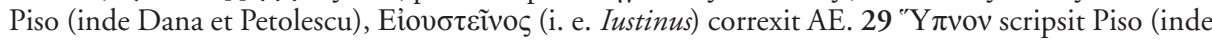
Petolescu) simulacrum dei putans (recte, ut videtur), v̌ $\mu v o v$ nulla necessitate coniecit Dana (inde AE).

Nexos: MN (1. 3: sollem $\left.{ }^{\wedge} n i a\right)$, AN (1. 3: $\left.a^{\wedge} n n u a\right)$, IN (1. 7: $i^{\wedge} n$ trat $)$, VM (1. 12: $\left.[h] o r t u^{\wedge} m\right)$. No hay interpunciones.

\section{Traducimos:}

"Hay unas fuentes géticas hijas de la divina Ninfa, a quien pertenece un hermoso terreno cercano a Germísara y en cuyo honor el soldado britano celebra fiestas anuales 
ofreciéndoselas en pago conforme a un voto; y cumple primero los votos del tiempo transcurrido y vuelve a asumir otros votos el jefe, a quien una cimera empenachada se le inclina hacia delante en lo más alto de su cabeza. Desde aquí entra en unas aguas de buenos efluvios [---] desde allí, de donde surgen una fuente nacida de la roca porosa y, de ella, un líquido salutífero, y se hacen [---] cuan grande [---] valor (?) [---] y a casa [---] por [---] años [---] y el jardín que había prometido mediante un voto [---] yo, el comandante, lo ofrendo [---] estarás ceñida por la vid de un [---] frondoso $y$, por haber sido juzgada merecedora de un dulce regalo, rodeada de racimos de uva. Te ruego, Odrisia, que, llena de alegría, guardes esta ofrenda.

Las Ninfas de Germísara, por haber hecho brotar una corriente [---], obtuvieron por la benevolencia del dios los dones de Asclepio, que los varones mortales, que han seguido su tratamiento, celebran. Llegaron lisiados $y$, tras haber hecho los votos adecuados, regresaron caminando rectamente y aportando ofrendas a Panacea; honrando a los benéficos baños, en acción de gracias, cumplieron sus promesas (aportándoles ?) agua (fresca ?) y potable; a Ártemis cazadora le hicieron las ofrendas prometidas, tortas de semillas, y celebraron cumplidamente las fiestas y sacrificios y se volvieron de regreso.

Justino, comandante de la guarnición britana, ofrendó esta estatua de Hypnos siendo gobernador el ilustrísimo Cándido.

Gayo Sencio Justino, centurión de la legión v Macedónica, operando por el territorio Lucano."

\section{CONSIDERACIONES GENERALES}

Estamos ante una inscripción votiva dedicada a las Ninfas (o a la Ninfa: cf. vv. 1 y 17) de las termas de Germisara por un centurión de la legio V Macedonica (estacionada en Dacia desde la época de Marco Aurelio: cf. Ritterling, RE XII.2, 1578, 66 ss., s. v. "legio") puesto entonces al frente (praepositus. vid. infra ad v. 13) del numerus peditum singularium Britannicianorum (cf. vv. 3 y 13 y l. 27 s.), unidad auxiliar formada por soldados originarios de Britania y acantonada en Germisara (cf. Piso, 2015: 48 y nota 7, así como Lassère, 2005: II, 789 s.). A juzgar por lo que se dice en 1.28 s., esta dedicación estuvo inducida por un sueño (vid. infra comm. ad loc.). El contenido de la inscripción se corresponde en muchos puntos con los hallazgos arqueológicos del lugar, junto con los cuales permite establecer una relación entre esta unidad militar y dichas termas, sobradamente atestiguada por las inscripciones y exvotos hallados en el lugar: hay más inscripciones votivas de Germisara dedicadas a las Ninfas y a otras divinidades ${ }^{1}$ por mandos de ese mismo numerus, quienes, junto con sus subordinados, frecuentaban este santuario termal y mostraban

${ }^{1}$ A las Ninfas (CIL III 1396 = ILS 2630: 186 d. C.; $A E$ 1992, 1487 = ILD 329: 201/230 d. C.), a Júpiter Óptimo Máximo (IDR III/3, 237: 238/244 d. C.), a Diana Augusta (AE2003, 1513 = ILD318: 211/217 d. C.) y a los di patroni (IDR III/3, 219: 201/270 d. C.). Cf. Bertolazzi, 2015: 186-189. 
su agradecimiento a las divinidades sanadoras, cuando no contribuían decididamente a la construcción y perfeccionamiento de las instalaciones. Traigamos a colación al respecto el carmen epigraphicum votivo Zarker $21=$ CLEAfr 4 (Gholaia, África Proconsular, 202/203 d. C.), mediante el cual un centurión dedicó a la diosa Salus

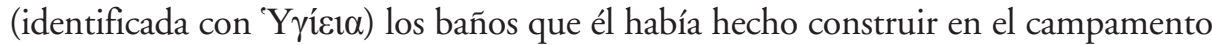
que servía de sede al destacamento (una uexillatio de la legio III Augusta) por él comandado.

La inscripción votiva que ahora nos ocupa se inscribe, asimismo, dentro de la tradición literaria y epigráfica de la poesía relativa a los baños (estudiada por Busch, 1999). No puede decirse que estemos ante una plegaria u oración como supone Piso ("ein Gebet") basándose en el verso con el que concluye el poema en latín (v. 16: te precor... ), ya que el hecho de que una inscripción votiva concluya con un ruego no quiere decir que ésta sea una plegaria: es bastante frecuente que un carmen epigraphicum votivo concluya con un ruego a la divinidad para que ésta acepte la ofrenda que se le dedica o para que, en lo sucesivo, sea propicia al dedicante (cf. Kühn, 1906: 33-35 y 67-71). Tampoco estamos ante un himno a las Ninfas como supone Dana conjeturando innecesariamente ớ $\mu$ vov en vez de vítvov (1. 29): esta conjetura no está suficientemente justificada; $y$, salvo la mención de las Ninfas y su posible vinculación con el culto de Asclepio en el recinto, bien atestiguado por otras inscripciones del lugar, falta en el texto cualquier elemento propio de la himnodia (epítetos cultuales, topográficos, origen de las divinidades, mención de sus esferas de poder, atributos, etc.).

En cuanto a la relación existente entre el texto latino y el texto griego, conviene observar que éste no es traducción sino complemento y amplificación de aquél.

\section{EL TEXTO LATINO}

Las líneas 1-16, escritas en latín, contienen un carmen en hexámetros dactílicos, que están perfectamente distribuidos en el campo epigráfico (hay coincidencia entre línea y verso) y que presentan ciertas peculiaridades e imperfecciones no ajenas a la poesía latina epigráfica y menos aún a la de la época imperial:

- abundancia de hiatos²: Germisarae ${ }^{\mathrm{H}} \overline{e s t}$ (v. 2), donde no hay la aféresis (e)st, sollem$n i \breve{a}^{\mathrm{H}}$ annua (v. 3); excessi ${ }^{\mathrm{H}}$ et (v. 5: en la cesura pentemímera); circumdată ${ }^{\mathrm{H}}$ unis (v. 15); $\operatorname{donu}^{\mathrm{H}}{ }^{\mathrm{H}}$ (h)ilarata (v. 16), donde hay además, según parece, un alargamiento en arsis ante cesura (vid. infra).

${ }^{2}$ Sobre la alta frecuencia del hiato en la poesía latina epigráfica, cf. Mariné, 1952: 130-131; Cugusi, 1996²: 61, nota 109 ${ }^{\text {bis; }}$ Courtney, 1995: 26-27. 


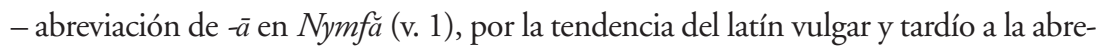
viación de las vocales átonas (generalmente en sílaba final), lo que guarda relación con el proceso de desaparición de las oposiciones de cantidad ${ }^{3}$.

- alargamiento en arsis ante cesura ${ }^{4}$ : ... dignatā // dono... (v. 15, ante la cesura pentemímera); ... Odrysiā // donūm ${ }^{\mathrm{H}} / /$ (h)ilarata... (v. 16, ante la cesura pentemímera y ante la heptemímera).

- el v. 3 es incorrecto por la inclusión de un nombre propio (Brittannicus); al v. 4 le falta una sílaba breve antes de la cláusula, esto es, su $4^{\circ}$ pie está incompleto (... soluītquĕ uōtă prīoră); hay consonantización de $u$ en fluentes (v. 7); el v. 12 es incorrecto por el crético de la secuencia quèmquĕ uōuerat (por lo demás, la cláusula es buena); el v. 13 es incorrecto por la inclusión del término institucional praepositus, si se acepta la lectura de Piso (hunc) para la palabra que sigue (vid. infra ad loc.).

En cuanto a la lengua y a la grafía, obsérvese: a) la transcripción de $\phi$ mediante $f$ en vez de phen $N y m f a$ (v. 1); b) las grafías arcaicas uortice (v. 6) en vez de uertice (cf. Quint. inst. 1, 7, 25) y rusum (v. 5) en vez de rursum (cf. Leumann 211); c) la ultracorrección formonsus (v. 2) en en vez de formosus, frecuentísima tanto en las inscripciones como en los manuscritos (cf. ThLL V.1, 1110, 81 ss.; Leumann 342); d) la omisión de $h$ inicial en ilarata (v. 16); e) Brittannicus en vez de Britannicus

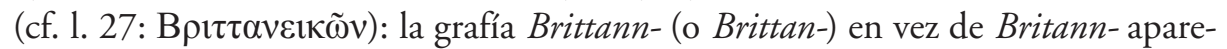
ce en Lucr. 6, 1106 (nam quid Brittannis... ) -con el consiguiente alargamiento de la primera sílaba-y es frecuente en las inscripciones desde el s. I d. C. (cf. ThLL II 2195, 12 ss. y 27 ss.; Leumann 184); y f) la abreviación -como la escansión evidencia

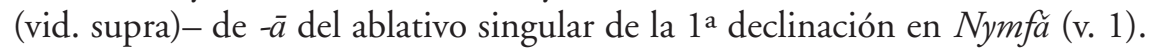

Se distinguen dos partes en este poema: a) la primera (desde el v. 1 hasta quizá el v. 11 -el contenido de los vv. 10 y 11 , muy mal conservados, es incierto) consiste en una descripción del santuario termal de Germisara y de su ager como un locus amoenus (v. 2: ager formonsus) y en una narración de las fiestas anuales (v. 3: sollemnia annua) que la unidad militar comandada por el dedicante celebrababa allí (obsérvese el uso del presente habitual) en honor de la Ninfa -llevándole ofrendas votivas y formulándole nuevos votos- en acción de gracias por la eficacia curativa de estas aguas termales; b) la segunda (vv. 12-16) conmemora el cumplimiento de un voto, llevado a cabo por el comandante de dicha unidad mediante una ofrenda consistente -según nuestra lectura del v. 12- en un jardín (hortus). Esta segunda parte es la propiamente dedicatoria (como el subscriptum en prosa: 1. 27-32) y podría constituir por sí sola una inscripción votiva. 1995: 25.

${ }_{3}^{3}$ Sobre este fenómeno en la poesía latina epigráfica, cf. Mariné, 1952: 133-135; Courtney,

${ }^{4}$ Sobre este fenómeno en la poesía latina epigráfica, cf. Mariné, 1952: 128-129; Courtney, 1995: 26; Cugusi, 19962: 246, nota $27^{\text {bis. }}$. 


\section{EL TEXTO GRIEGO}

Las líneas siguientes (17-30) contienen un texto griego en prosa pero con cierto color poético. Este texto está redactado en una lengua incorrecta y confusa, que, si bien permite captar el contenido fundamental de la inscripción, arroja muchas dudas sobre su sentido y propósitos estilístico y ritual. A diferencia del texto latino, resulta punto menos que imposible establecer una unidad de sentido. La información que el texto griego aporta resulta ser complementaria de la del texto latino, con detalles sobre los beneficios terapéuticos obtenidos por la guarnición, sobre las fiestas y sacrificios realizados, sobre las divinidades del recinto y sobre la identidad del dedicante.

La torpeza e imprecisión del texto se muestra ya en los errores de grafía inducidos por la evolución del vocalismo griego y por la desaparición de las oposiciones de cantidad. En la fecha de la inscripción (finales del siglo II d. C.) se han producido ya todos los yotacismos -salvo la confusión del diptongo or con $v$ (cf. Palmer,

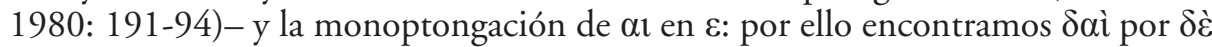

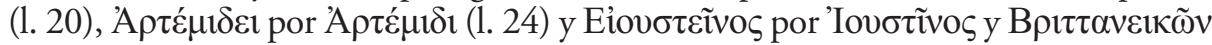

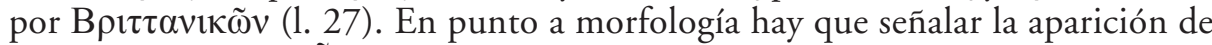
formas tardías como $\tilde{\eta} \lambda \lambda \theta \alpha$ (1. 21) y $\dot{\varepsilon} \pi \alpha v \tilde{\eta} \lambda \theta \alpha \nu$ (1. 26) con desinencia analógica de la de los aoristos sigmáticos. Es notable la aparición de formas poéticas como los aoris-

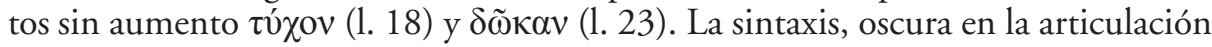
de las frases, muestra también el deseo de dar un cierto color poético al texto: así,

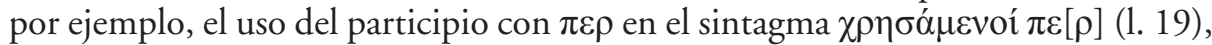
frecuente en poesía ya desde los poemas homéricos aunque con un valor concesi-

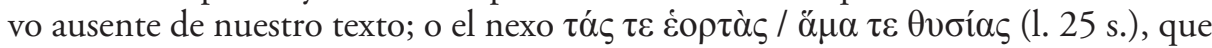

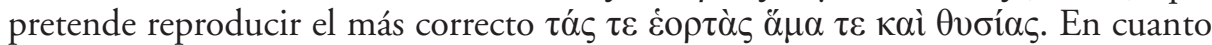
al léxico, es de notar la aparición de algunos términos poético-litúrgicos como vọ̃ $\mu \alpha$

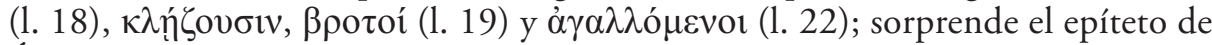

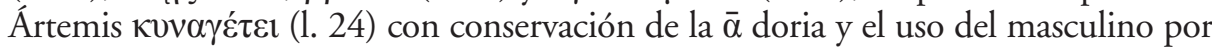
el femenino, con desinencia de dativo - $\varepsilon 1$ por $-\eta$. Todo ello compone un texto estilísticamente confuso, con formas de resonancias poéticas junto con formas tardías propias de la lengua hablada y alguna (vid. infra ad 1.17 ) propia de la jerga científica.

Como ya hemos dicho, en el estado actual de la inscripción resulta imposible reconstruir un texto sintáctica y estilísticamente unitario. El texto griego nos informa, en consonancia con el texto latino pero de forma más pormenorizada: a) de dones $\mathrm{y}$ actos de agradecimiento a las divinidades de las termas (las Ninfas, Asclepio, Panacea, Ártemis e Hypnos); b) de la celebración de un festival que comportaba sacrificios (1. 25 s.); c) de una curación o sanatio (l. 19 s.), relatada de modo semejante a como se narran los ió $\mu \alpha \tau \alpha$ de Epidauro y de otros Asclepieos5 ; d) quizás de la construcción

${ }^{5}$ Para la tipología de los ió $\mu \alpha \tau \alpha$ o sanationes véase Guarducci, 1987: 301-306, donde se estudian los testimonios de Epidauro, Lebena y Roma. 
de una fuente con agua potable para las necesidades del ritual y de los consultantes (1. 23); y e) del ofrecimiento de un "Y $\pi v o v$ (1. 28 s.), una estatua de la divinidad paredra de Asclepio. Obsérvese que, a diferencia del texto latino, en el que la Ninfa es la única divinidad mencionada, el texto griego se refiere a más divinidades; hasta los propios baños aparecen en él como personificados y divinizados: se menciona una ofrenda consagrada a ellos en acción de gracias (l. 22 s.).

El texto griego de las líneas 27-30 constituye, junto con el texto latino de las dos líneas siguientes (31 s.), el habitual subscriptum en prosa ${ }^{6}$, que en este caso contiene: una fórmula de dedicación, junto con la indicación de la fecha (mediante el nombre del gobernador) y la identificación precisa (jurídica) del dedicante (nombre, graduación militar, legión a la que estaba adscrito, numerus puesto bajo su mando y ámbito territorial de actuación).

\section{COMENTARIO}

1 Getici fontes: cf. Getico fonte en Ov. trist. 4, 8, 26.

diuina Nymfa creati: el uso del participio creatus con un ablativo de origen y como sinónimo de natus (o filius) es, sobre todo, poético: cf. ThLL IV, 1160, 7 ss., K.-St. 1, 375, H.-Sz. 104 y, p. ej., Ov. fast. 3, 409: Ampelon intonsum satyro nymphaque creatum. Por su parte, Nymfa debe entenderse como singular colectivo (compárese con el nominativo plural Nú $\mu \varphi \alpha$ del texto griego -1. 17- y con el dativo plural Nymphis empleado en todas las inscripciones latinas votivas en prosa dedicadas a las Ninfas en estas mismas termas -véase el catálogo de Piso, 2015: 66-67) y como otro poetismo ${ }^{7}$ al igual que en la otra inscripción votiva en verso -el epigrama CLE 864 (= CIL III 1395), 2- hallada en este mismo lugar: regina undarum Nympha, decus nemoru $[\mathrm{m}]^{8}$. Ahora bien, el ruego de v. 16 parece estar dirigido a una ninfa determinada, designada mediante un nombre o epíteto local (vid. infra ad loc.).

2 ager uicinus Germisarae: que estas termas estaban cerca del fuerte de Germísara (vid. supra) se dice también en el epigrama CLE 864 (cit. supra ad v. 1), 4: moenitae propter moenia Germisarae. En cuanto al término ager, debe entenderse aquí como el terreno cultivado en el perímetro de estas termas y consagrado, a modo de $\tau \varepsilon ́ \mu \varepsilon v o \varsigma$, a las Ninfas; tiene que tratarse del ager en el que el dedicante plantó como exvoto el hortus mencionado -según nuestra propuesta de lectura- en v. 12.

3 miles Brittannicus: singular colectivo (compárese con el plural del texto

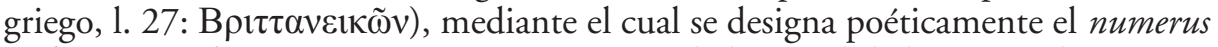
peditum singularium Britannicianorum, comandado por el dedicante (vid. supra).

${ }^{6}$ Las inscripciones en verso suelen ir acompañadas de una parte en prosa (praescriptum o subscriptum) que contiene indicaciones esenciales.

${ }^{7}$ Sobre el singular colectivo en la lengua poética latina, cf. Janssen en Lunelli, 1988³: 104-105.

${ }^{8}$ Epigrama de dos dísticos elegíacos y cuyo dedicante debe de ser C. Iulius Bassus (PIR ${ }^{2}$ I 206), gobernador provincial de Dacia entre el año 135 y, según parece, el 139 d. C. 
3-4 En el texto griego (1.25) se dice lo mismo pero con respecto al culto rendido a Ártemis. En cuanto a sollemnia... ducit, cf. Verg. georg. 3, 22: ... sollemnis ducere pompas, en cuanto a sollemnia... I ex uoto referens (la lectura de Piso, efferens, es errónea), donde el verbo refero está empleado en su acepción de 'ofrecer en pago',

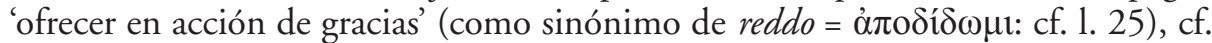
Verg. Aen. 5, 605: dum uariis tumulo referent sollemnia ludis (ecl. 5, 74 s.: ... cum sollemnia uota / reddemus Nymphis...) y Sil. 5, 181: dona serenato referas sollemnia Phoebo, así como la fórmula uotum referre, que sirve para expresar el cumplimiento de un voto (como uotum reddere y como uotum soluere, que es la fórmula votiva más habitual) ${ }^{9}$. Por lo que se refiere a la epigrafía votiva en verso, cf. CIL IX $3375=$ CLE 250 (Aufinum, Regio Italiae IV, a. 156 d. C., dedicación a Silvano), 13 s.: dum tibi quae refero quaeq(ue) aris, inclute, reddo / ex uoto meritoque libens mea dicta resoluo.

4 priora: lo entendemos como predicativo (sobre el uso de prior, -is con función predicativa o en vez de un adverbio como antea, cf. ThLL X.2, 1322, 57 ss.); de no ser así, habría que admitir una redundancia: ... uota priora / temporis excessi...

5 ipse: según parece, el propio centurión (el dedicante) por oposición a sus subordinados (los soldados del numerus puesto bajo su mando, mencionados en v. 3) y conforme al uso de ipse como pronomen honoris, esto es, por la misma razón por la que este pronombre sirve para referirse al dominus (por oposición a los serui) y, en general, a quien tiene preeminencia sobre otros (cf. ThLL VII.2, 341, 6 ss., y E.-M. 322, s. v.).

6 cui: Piso cree que este relativo se refiere, como el que encabeza también -a modo de anáfora- los versos 2 y 3 , a la Ninfa (v. 1) y traduce: "Vor der sich (vor den Nymphe)..." (interpretación seguida por Boëls, Follet y Puech: "C'est pour elle que s'incline...", así como por Petolescu). De ser así, el verbo procumbo estaría empleado aquí en su acepción de 'inclinarse' o 'postrarse' ad precandum, venerandum (cf. $T h L L$ X.2, 1567, 59 ss.), y el penacho mencionado sería un símbolo de la autoridad militar, que se inclina piadosa ante el poder terapéutico de la Ninfa. Ahora bien, por razones lingüísticas creemos que es preferible entender dicho cui como referido al ipse inmediatamente precedente (en el sistema de la lengua latina, lo normal es que entre un pronombre demostrativo y un pronombre relativo que le sigue haya una correlación) y como dativo simpatético. El casco descrito en este verso como provisto de un penacho (cristatus apex) ${ }^{10}$ es, por tanto, el del centurión praepositus; lo que permite suponer que los cascos de los milites Britannici puestos bajo su mando no tenían penacho. Desde el punto de vista de la tradición literaria, estamos ante una descripción del casco para la que pueden citarse bastantes loci similes. Verg. Aen. 12, 492 s.: ... apicem tamen incita summum / hasta tulit summasque excussit uertice

${ }^{9}$ Sobre el uso de estas fórmulas en las inscripciones latinas votivas, cf. Roth, 1935: 60-61.

${ }^{10} \mathrm{La}$ cimera del casco, llamada apex o conus, consta de un soporte y del penacho, llamado crista: cf. S. Reinach, $D A$ II.2, 1434 s., s. v. "galea". 
cristas, 10, 270 s.: ardet apex capiti cristisque a uertice flamma / funditur...; App. Verg. Ciris 501: pumiceam concussit apex in uertice cristam; Germ. Arat. frag. 2, 3 Gain: ... cristatus uertice Mauors; Sil. 16, 120: uertice fulsit apex..., 1, 401: ... cristatae cassidis aera.

uortice summo: cláusula heroica recurrente (Catull. 64, 390; Ov. met. 4, 731; App. Verg. Ciris 319; Sil. 12, 152); uortex summus designa en este verso la coronilla, como en la expresión proverbial ab imis unguibus usque ad verticem summum (Cic. QRosc. 20): cf. Otto, 1890: 355 s. (no 1822, 1).

7 hinc undas...: cf. el inicio de verso de Ov. ars 3, 177: hic undas... En cuanto a nuestra propuesta de lectura (binc undas $i^{\wedge} n t r a[t]$ bo [n] a fluentes -hay que suponer una consonantización de $u$ en flu da en Stat. Theb. 9, 471 s.: ... uenientesque obuius undas / intrat... ; y bo [n] a fluentes puede explicarse como una construcción de acusativo interno (cf. Lucan. 10, 315: ... lene fluentem) o por un uso transitivo de fluo (esto es, como sinónimo de effundo o emitto), bien atestiguado en el latín tardío: cf. K.-St. 1, 278; ThLL VI.1, 970, 53 ss.; p. ej., Aug. c. Faust. 15, 6: flumina dulce nectar fluunt (cf. también Petron. 71, 11: ne effluant uinum). En cuanto al adverbio illinc, que creemos distinguir al final del verso, se halla en la misma posición métrica en Ovidio (met. 1, 618; 4, 71; 15, 165) y en Virgilio (Aen. 4, 442).

$8 \mathrm{El}$ adjetivo pumiceus (que proponemos leer) se aplica aquí a la fuente de aguas termales porque ésta mana de rocas porosas (el sustantivo correspondiente, pumex, designa, no sólo la piedra pómez, sino también otras piedras porosas: cf. Blümner, $R E$ III.1, 473, 36 ss., s. v. "Bimsstein"; M. Besnier, $D A$ IV.1, 767, s. v. "pumex"; ThLL X.2, 2635, 55 ss., s. v. "pumex"), como en Mart. 4, 57, 2: et quae pumiceis fontibus antra [sc. Baiarum] calent ${ }^{11}$; cf. también Lucan. 4, 300: ... noui percusso pumice fontes, y Claud. rapt. Pros. 2, 103: ... uino de pumice fontes. Dicho adjetivo se aplica también, como es natural, a las las grutas formadas por piedras porosas; de ahí su uso poético referido a los antros de las Ninfas: cf. Sil. 7, 419: pumiceaeque procul sedes [sc. Nereidum] ...; Stat. silv. 3, 1, 144: ipsae pumiceis uirides Nereides antris.

9 Según nuestra propuesta de lectura, estaríamos ante un uso del verbo ex(s)urgo como cuasisinónimo de profluo: cf. ThLL v.2, 1959, 40 ss., y p. ej. Mela 1, 39: ille [sc. fons] inmodicus exurgit, y Comm. apol. 958: omni loco fontes exsurgunt e se parati.

10 A la secuencia inicial VIR siguen un resto de letra identificable con T y una laguna, causada por la rotura del soporte. Piso leyó uirtus [---] creyendo ver otros dos restos de letras e identificándolos con VS; pero resulta difícil distinguir,

${ }^{11}$ Cf. comm. ad loc. de Moreno, 2006: 408. Según ThLL X.2, 2636, 51 s., en este verso de Marcial dicho adjetivo significa "e pumice ortus" o, quizá, "pumice infectus". 
al menos en la fotografía, tales restos. Por tanto, no es segura la lectura uirt [us ---] o uirt [ut---] (una forma del mismo sustantivo distinta del nominativo singular), que se referiría al valor de los soldados. Teniendo en cuenta, además, que después de las tres primeras letras de este verso parece distinguirse un pequeño espacio en blanco, quizá sería preferible leer uir t[---] (compárese con inicios de hexámetro como uir Troiane... -Verg. Aen. 10, 598 y 11, 125- y como uir tanto... -Ov. Pont. 4, 10, 76): el nominativo singular uir podría referirse al dedicante o -si se tratase de un singular colectivo- a los soldados puestos bajo su mando (uir estaría empleado como sinónimo de miles). En cuanto al final de este verso, y según nuestra propuesta de lectura, estamos ante un tipo recurrente de cláusula heroica; cf. Verg. Aen. 8, 490: ... ipsumque domumque (Stat. Theb. 5, 639); Ov. her. 5, 117: ... patriamque domumque; Lucan. 6, 803: ... patremque domumque; Val. Fl. 1, 769: ... natumque domumque; Sil. 6, 378: ... murosque domumque.

11 Podría conjeturarse un segundo hemistiquio del tipo multos / longos... in annos "por muchos / largos años" (cf. p. ej. Ov. ars 1, 425, fast. 5, 33, am. 2, 19, 23; Tib. 3, 8, 23; App. Verg., Eleg. in Maecen. 1, 117; Stat. silv. 3, 5, 107).

12 ... quemque uouerat [h]ortu^ $m$ : en cuanto a la construcción sintáctica, cf. el epigrama CLE 867 = CIL x 3812 (Capua, Regio Italiae I, s. II d. C.): ... quam uouerat aram /... posuit. En cuanto al objeto de la dedicación (un hortus según nuestra propuesta de lectura), cf. la inscripción en prosa $A E$ 1933, 46 = 2015, 1842 (Calceus Herculis, África proconsular, 209/217 d. C.), cuyo dedicante es también un centurión puesto al frente (praepositus) de un numerus y mediante la cual se conmemora el mismo tipo de ofrenda (un hortus) a otra divinidad: Deo Soli I (h)ortum conIstitutum per | C. Iulio Aelulrione (centurione) [leg(ionis) I [II]I Aug(ustae) Anton(i)|nian(a)e $\operatorname{pr}($ a)ep(osito) I n(umeri) Hemesen(orum). Por lo que se refiere a la tradición epigramática latina relativa a los baños termales, cf. Anth. Lat. 179, 3 Riese'2 hic quoque pomiferum coniunxit sedulus hortum (Busch, 1999: 323-325). En cuanto a la epigra-

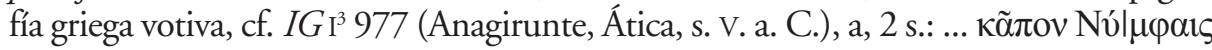
$\dot{\varepsilon} \varphi v ́ \tau \varepsilon v \sigma \varepsilon v$. Era costumbre adornar con jardines las inmediaciones de las grutas y fuentes consagradas a las Ninfas (cf. G. Lafaye, $D A$ III.1, 278, s. v. "hortus").

13 Inmediatamente después de la laguna, causada por la rotura del soporte, creemos distinguir la terminación -us, correspondiente quizá al cognomen del dedicante (Iustinus: cf. 1.27 y 31), quien es mencionado a continuación mediante el término praepositus, que designaba al comandante de un numerus (cf. R. Cagnat, $D A$ IV.1, 118 , s. v. "numerus", y 624, s. v. "praepositus") y que en el texto griego (1. 28) es tradu-

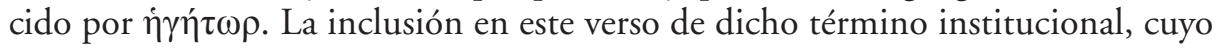
uso no es poético ${ }^{12}$, resulta amétrica, si es que la lectura de Piso de lo que sigue (bunc

${ }^{12}$ No hay en los poetas ningún ejemplo del uso del participio de perfecto masculino de praepono como sustantivo (praepositus, -i): cf. ThLL X.2, 775, 18; también es raro en la poesía dactílica, excepto en Ovidio (21 ejemplos), el uso de cualesquiera formas del verbo praepono: cf. ThLL X.2, 769, 20. 
tibi [---) es correcta: se trata, a nuestro juicio, de una lectura incierta, que el examen de la fotografía no confirma. Es más, en lugar de ese supuesto tibi creemos distinguir la forma verbal fero, que estaría empleada para expresar la ofrenda votiva como en dona ferens (CLE 868, 2) y en uota ferens (CLE 259, 3); cf. supra v. 4: (ex noto

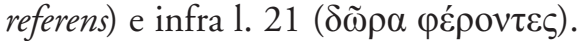

14 De acuerdo con la métrica, hay que leer ---Jrè (seguramente un adverbio en -ē: quizá propere) cingeèrīs (futuro), secuencia correspondiente a los pies $3^{\circ}$ y $4^{\circ}$ del hexámetro y dentro de la cual se distingue la regular cesura pentemímera. Hay que descartar la lectura recingeris - propuesta por Boëls, Follet y Puech, quienes traducen: "tu es (seras ?) a nouveau cinte"- por dos razones: a) porque constituiría una secuencia que no encajaría en el metro, tanto si se tratase de un presente (rěcingěrišs) como si se tratase de un futuro (rěcingèreìs); y b) porque el verbo compuesto recingere ('desceñir' o 'desatar') no sería semánticamente coherente con el contexto, a no ser que estuviese empleado aquí -como dichos autores creen-con la acepción de iterum cingere ('volver a ceñir'), que es extremadamente rara y muy tardía (cf. ThLL XI.2, 325,67 ss.).

uite: la vid (o la viña) que crecerá en el jardín dedicado a la Ninfa; pero quizá haya también una alusión a la graduación militar del dedicante, por cuanto uitis era el nombre de la vara de mando del centurión, consistente en un sarmiento (cf. V. Chapot, $D A$ v, 929, s. v. "vitis").

comati: genitivo singular masculino o neutro (la sintaxis excluye la posibilidad de que se trate de un nominativo plural masculino) del adjetivo comatus, - $a$, -um y, a juzgar por el contexto, con el sentido translaticio de 'frondoso' como en comata silua de Catull. 4, 11 (único ejemplo que, de este uso, se recoge en ThLL II 1756, 47 ss.); por lo que hay suponer para la laguna inicial de este verso un sustantivo en genitivo como horti o agri. Según Piso, comati podría ser aquí un insólito ablativo singular femenino analógico de los temas en - $i$ de la tercera declinación, de modo que uite comati equivaldría a uite (o uiti) comata; pero ello es una suposición demasiado forzada y difícil de admitir.

15 Obsérvese, desde el punto de vista estilístico, la fuerte aliteración de todo este verso tal como lo hemos leído (véase el aparato crítico).

[dul]ci dignata dono: uso del participio de perfecto dignatus, $-a$, $-u m$ con el significado pasivo de dignus habitus (esto es, como participio de digno, no del deponente dignor) y dentro de la construcción del tipo aliqua re dignatus "tenido por digno o merecedor de algo" (cf., p. ej., Verg. Aen. 3, 475: coniugio, Anchisa, Veneris dignate superbo; Sil. 11, 272: ipse deum cultu et sacro dignatus honore); cf. también la expresión dulci digne mero de Hor. carm. 3, 13, 1, donde se trata de la ofrenda a una fuente (al fons Bandusiae).

circumdata unis: adaptación al femenino, con el consiguiente hiato, de la cláusula de Ov. met. 3, 666: ipse racemiferis frontem circumdatus unis, verso referido a Baco.

16 El contenido de este verso, con el que concluye el poema en latín, corresponde al tópico ruego a la divinidad para que acepte la ofrenda (cf. Kühn, 1906: 3335, y p. ej. CLE 249, 3: acipe quae pietas ponit tibi dona merenti; CLE 1841, 1: Accipe, P[h]oebe, pre[cor], ... munera...; CLE 868, 5: sume libens simulacra...; CLE 873, 2: 
accepta ut tibi sint, numen adoro tuum; Zarker $5=$ CLEHisp 144, 4 s.: tu tantum, quaeso, mente propitia accipe / qua [e] tibi dicamus...), si bien el verbo recondo no es nada habitual para formular dicho tópico; en cuanto a donum... recondas, cf. Ov. her. 11, 98: pectoribus condam dona paterna meis.

te precor: la misma fórmula, también como inicio de hexámetro y seguida del vocativo de la divinidad, en el epigrama votivo (del que acabamos de citar otro verso) CLE 868, 1: Te precor, Alcide... (= Verg. Aen. 10, 461).

Odrysia: vocativo del adjetivo Odrysius, $-a$, -um, correspondiente al etnónimo Odryssae, -arum u Odrysii, -orum: los odrisios, pueblo tracio cuyo nombre suele emplearse para designar a toda la Tracia. Su uso como nombre o epíteto local de la Ninfa puede explicarse por el mito de la ninfa Argíope, que dio a luz a Támiris en el país de los odrisios (cf. Stoll, Lex. Roscher I, 501, 53 ss.; Hiller von Gaertringen, $R E$ II.1, 719, 8 ss.).

ilarata (= hilarata): este participio (que proponemos leer) sirve aquí para indicar la alegría de la divinidad por la ofrenda recibida (cf. CLE 872: Belus... / ara gaudebit...). No hay más ejemplos del verbo hilaro referido a dioses (cf. ThLL VI.3, 2786, 24 ss.) pero sí de su compuesto exhilaro (Mart. 8, 49, 6: exhilarant ipsos gaudia nostra deos) y del adjetivo hilaris, -e. cf. ThLL vi.3, 2787, 18 s., y p. ej. Sil. 8, 182: ... hilares... Nymphae; Apul. met. 10, 34, 1: Venus uero gaudens et hilaris...

17-19 Estas líneas, las tres primeras del texto griego, son una alabanza de las termas de Germísara y de su origen divino y vienen a ser una amplificación de los dos primeros versos del poema en latín, expresando el mismo propósito de situar las termas en la esfera del culto de las Ninfas y añadiendo a ello la mención expresa de Asclepio.

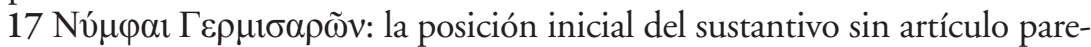
ce sugerir un vocativo que, seguido de una determinación del lugar, constituye fórmulas poéticas frecuentes en inscripciones y epigramas; así, por ejemplo, en el no 5375

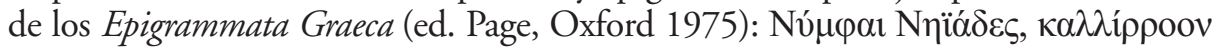

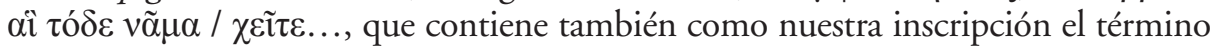
$v \tilde{\alpha} \mu \alpha$; expresiones semejantes encontramos en los epigramas 782, 1973 y 5455 de la misma colección. Pero, a pesar del parecido léxico y sintáctico, no es posible llevar más lejos la comparación, dado que en la inscripción Nú $\mu \varphi \propto \iota$ parece funcionar como

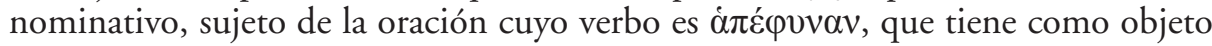
el acusativo vọ̃ua de la línea siguiente: el contenido de esta oración corresponde al

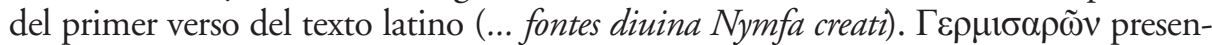
ta un inesperado genitivo plural para el topónimo (la forma griega atestiguada en Ptol. Geog. 3, 8, 4 es, como la latina Germisara, un singular de la primera declinación -cf. Patsch, $R E$ VII.1, 1263, 60 s., así como Detschew, 1957: 103), lo que permite formar un $\kappa \tilde{\omega} \lambda$ ov dactílico como inicio del texto; pero ello no debe inducirnos a pensar que la inscripción sea métrica, ya que -a pesar de la existencia de esta secuencia y de otras semejantes en el texto- resulta imposible establecer una estructura métrica reconocible.

vं $\pi+++++++\gamma \grave{\alpha} \rho \dot{\alpha} \pi \dot{\varepsilon} \varphi v v \alpha[v]$ : quizás se oculte aquí un adjetivo con el significado de 'subterránea' - lo que haría referencia a la conformación física del lugar

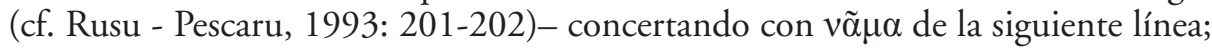




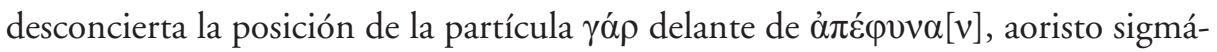
tico transitivo creado a partir del radical e intransitivo ảmé $\varphi v v$; es interesante notar,

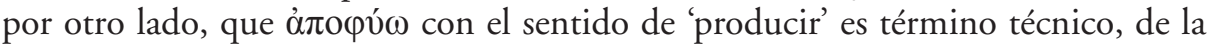
lengua de la botánica o de la medicina, relativamente tardío, atestiguado en Teofrasto

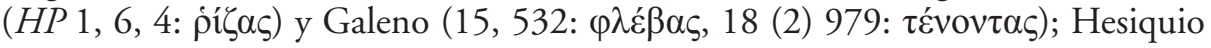
(s. v.) lo glosa como 'separar'.

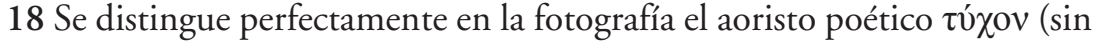
aumento, como $\delta \tilde{\omega} \kappa \alpha v$ de l. 23), con un complemento en acusativo $\delta \tilde{\omega} \rho \alpha$ ("obtuvieron los dones"); esta construcción de $\tau \vartheta \gamma \chi \alpha ́ v \omega$ con acusativo, aunque menos frecuente que la de genitivo, está sobradamente atestiguada ( $L \& S$ B II b, s. v.). Debe,

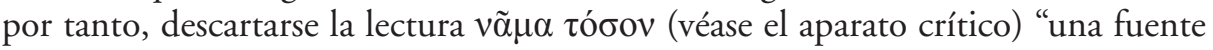
o corriente tan grande", que no responde a la sintaxis griega y que, de ser cierta, debería ser entendida como un latinismo, esto es, como un uso de $\tau$ ó $\sigma o \varsigma,-\eta$, , -ov con el significado de tantus, - $a$, - -um, del que en L\&S hay registrados sólo dos ejemplos: en Opiano de Apamea (Cyn. 2.183) y en un papiro del siglo II d. C. (PSI9, 1030, 16).

$\pi \rho o v o i ́ a:$ la benevolencia de Asclepio hacia la humanidad fue pronto hipostasiada en una divinidad paredra: así, por ejemplo, en el Asclepieo de Epidauro, donde Прóvol $\alpha$ aparece como destinataria de una dedicación ( $I G$ IV $1318=\mathrm{IV}^{2} 1$, 558 -cf. Höfer, Lex. Roscher III. 2, 3121, 17 s.); en Gortina (Kaorouzu, BCH 79,

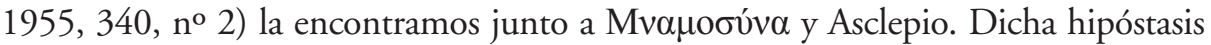
encontró una cierta difusión a partir de un momento difícil de determinar. Entendemos que en este contexto $\delta \tilde{\omega} \rho \alpha$ hace referencia a las mercedes que Asclepio concede a sus fieles: así, por ejemplo, en Libanio, Ep. 362, 5, donde un tal Marcelo acude al templo de Asclepio a consultar sobre el modo de tener descendencia; sus hijos son, en consecuencia, А $А \kappa \lambda \eta \pi \iota \tilde{~} \delta \tilde{\omega} \rho \alpha$.

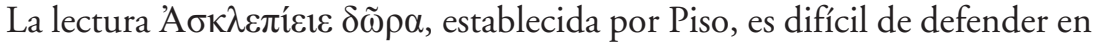
el contexto sintáctico, por lo que el propio Piso (seguido por los redactores de L'Année

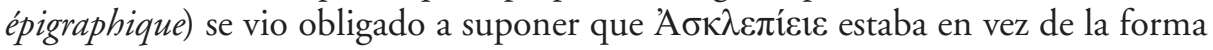
adjetival de acusativo plural neutro A $\sigma \kappa \lambda \eta \pi i \varepsilon 1 \alpha$. De ser así, estaríamos ante el sintag-

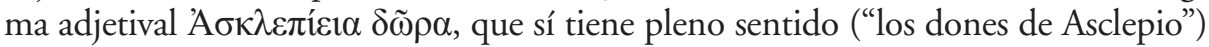
y que halla paralelo en otros sintagmas adjetivales que contienen ese mismo adjetivo y que están empleados por autores tardíos para referirse a objetos del culto de

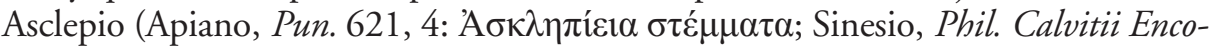

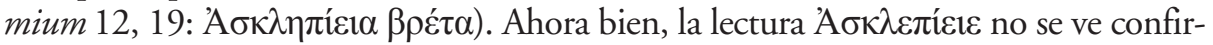
mada por el examen de la fotografía: nosotros vemos $\mathrm{A} \Sigma \mathrm{K} \Lambda \mathrm{H} \Pi \mathrm{H} O \mathrm{O}$, esto es, el genitivo A $\sigma \kappa \lambda \varepsilon \pi \iota_{0}$ (cf. Lib. Ep. 362, 5, cit. supra) con omisión de Y al final de la palabra, como ocurre con frecuencia en inscripciones griegas de diferentes épocas (cf. la grafía A $\sigma \kappa \lambda \eta \pi \imath \hat{o}$ en vez de A $\sigma \kappa \lambda \eta \pi \imath$, atestiguada en inscripciones áticas del s. IV a. C.: Syll. ${ }^{3} 1040=I G \mathrm{II}^{2}$ 4962, 1. 13; $I G \mathrm{II}^{2} 47,1.24$ y 26).

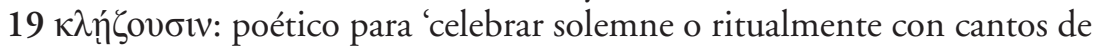
alabanza’ ya desde Homero (h. Hom. 31, 18; Pi. O. 1.110; E. IA 1522; Ar. Av. 921).

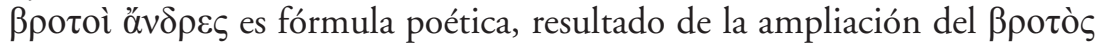
àví $\rho$ de Ilíada 5, 361 y raramente atestiguada en Odisea 5, 197, Hes. Op. 3, App. Anth. 163, 6. 


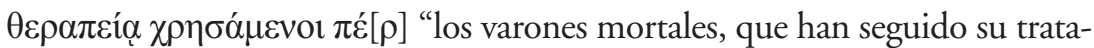
miento": ya hemos hecho referencia a la prosapia poética del participio con la partícula, así como a la incorrección de su uso, dado que aquí no hay valor concesivo; el sintagma proporciona, sin embargo, una secuencia métrica conveniente para dar tono poético al texto.

20. Nuestra interpretación lee íkavòv como objeto interno de $\varepsilon v ̉ \xi \alpha ́ \mu \varepsilon v o$ o "tras haber hecho suficientes, i. e. adecuados, votos" (también Piso escribe íkavóv,

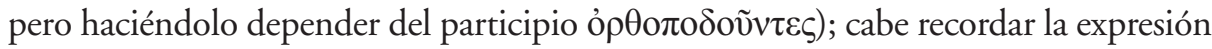

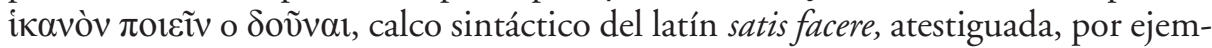
plo, en el Evangelio de Marcos $(15,15)$ o en los PSI 6.554, 22, y P. Oxyr. 294, 23.

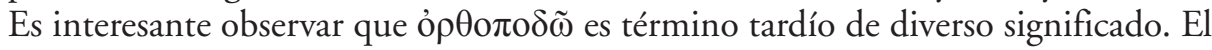
compuesto, clara derivación de la forma adjetival ỏ $\theta$ ó

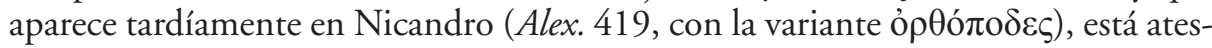
tiguado en griego en autores tardíos cristianos con el sentido de 'progresar, marchar': así en el Nuevo Testamento, Ep. Gal. 2, 14'13. En el suplemento del Greek-English Lexicon de Liddell \& Scott se corrige la entrada ỏ $\rho \theta 0 \pi \delta \delta \tilde{\omega}$ del diccionario con la traducción "walk...uprightly" por "advance, make progress", al igual que ỏ $\rho \theta$ o $\pi$ o $\delta i ́ \alpha$, traducida por "going straight forward, success" sobre la base del papiro del P. Univ. Milan 24. 8 del siglo II d. C, al que Winter (1941) añade un precioso testimonio de un papiro de la colección de la Universidad de Michigan (no 337 del inventario). Tal es también el sentido del verbo en un apotegma de los padres cristianos (no 395, 1. 8 Nau 1907-13) donde no cabe otra interpretación que la de 'caminar, andar por

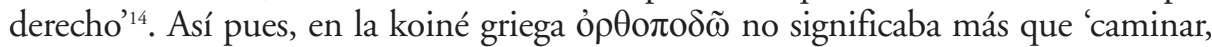
avanzar rectamente, progresar'. De ser éste el sentido en nuestra inscripción, cabe pronunciarse en favor de la interpretación que hace de íavòv un acusativo interno de $\varepsilon v ̉ \xi \alpha ́ \alpha \varepsilon v 0$ : "como llegaran lisiados, cuando ya caminaban derecho, tras haber hecho los votos adecuados, regresaron", que resulta en una interpretación aceptable y más próxima a la reiteración del texto latino. Es posible, sin embargo, otra inter-

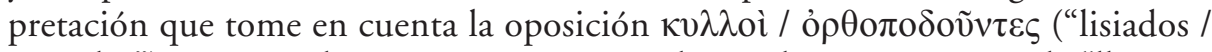
erguidos"), así como la que parece corresponder también a una esperada "llegaron

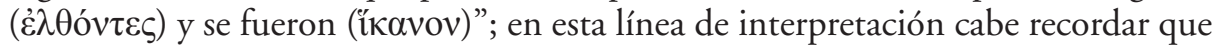
íóv $\omega$ está atestiguado con el sentido de 'irse': así, por ejemplo, en Esquilo, A. 1337 o Pers. 159.

21-26 Esta sección desarrolla toda la actividad litúrgica y ritual presentada ya en el texto latino: la festividad religiosa anual (v. 3), el ofrecimiento de ofrendas prometidas (v. 4 s.) y la renovación de los votos (v. 5).

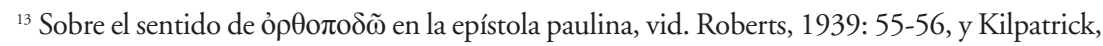
1957: 269-274.

${ }^{14}$ La burra parlante del apólogo se dirige a su dueño, que la ha golpeado por negarse a cami-

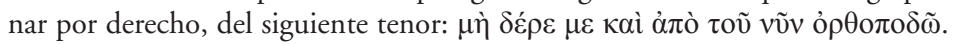


21 Las ofrendas a Panacea en el contexto del culto de Asclepio están atestiguadas ya desde los primeros textos relativos al dios de la medicina. En cuanto al ritual de la incubatio, que implicaba purificaciones, sacrificios y promesas de ofrendas como vemos ya en el testimonio más explícito de dicho culto en Pluto de Aristófanes (vv. 640 ss.), vid. Gil, 1969: 349 ss. ("La medicina sacra de Asclepio"). En cuanto a Panacea y demás divinidades asociadas a Asclepio, Epione, Hygíeia, Iasó, Akesó, Panacea, Pronoia, Hypnos, Telesforo, los Perros, vid. Gil, 1969: 361-363; véase también Edelstein, 1945: I, testimonios 283-296.

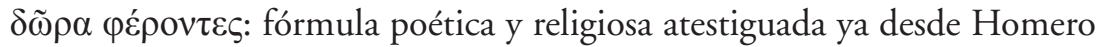

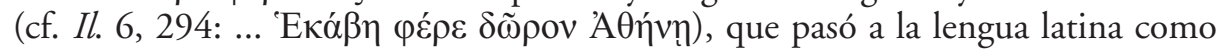
dona ferentes, cláusula virgiliana (Aen. 2, 49). A diferencia de los $\delta \tilde{\omega} \rho \alpha$ de 1. 18, que son los dones recibidos de la divinidad, éstos son las ofrendas consagradas a la divinidad, como los $\delta \tilde{\omega} \rho \alpha$ de 1.24 (y como el donum de vv. 15-16). Este uso del sustantivo $\delta \tilde{\omega} \rho o v$ es poético, por cuanto se da, sobre todo, en las inscripciones en verso y en los epigramas de la Antología Palatina: cf. Dittenberger ad Syll. ${ }^{3} 1141$, así como Kühn, 1906: 44).

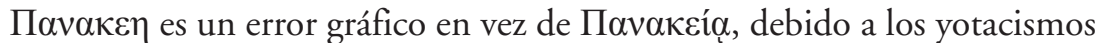
que afectaron a la correcta grafía de la palabra.

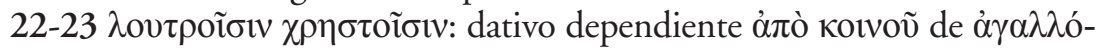
$\mu \varepsilon v o l$, que es término poético-religioso para 'honrar, glorificar' especialmente a un dios y atestiguado en estos usos ya desde Homero, y de $\delta \tilde{\omega} \kappa \alpha \nu$ (esta forma de aoristo, sin aumento, es -como hemos dicho ya- otro poetismo). El texto aparece aquí en este punto (tras $\delta \tilde{\omega} \kappa \alpha v)$ muy dañado, permitiendo leer sólo KHPA+++, la terminación [---] ov $\tau \varepsilon \varsigma$-correspondiente sin duda al nominativo plural de un participio

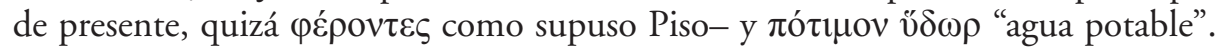
La secuencia KHPA+++ se distingue claramente, y el primer resto de letra -el que sigue inmediatamente a $\mathrm{A}$ - parece corresponder a $\mathrm{M}$, lo que permitiría leer una forma como kń $\propto \mu$ ọy (sustantivo que designa tanto la arcilla como cualquier recipiente $-\mathrm{u}$ otro objeto- de cerámica) con $\eta$ en vez de $\varepsilon$, si bien la forma con eta es exclusiva del dialecto de Chipre: en tres de las inscripciones sobre cerámica del ninfeo de Kafizin, editadas muy competentemente por Mitford y fechadas en 225/218 d. C.,

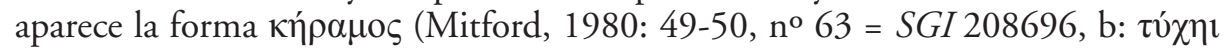

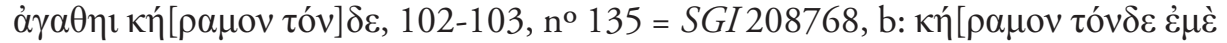

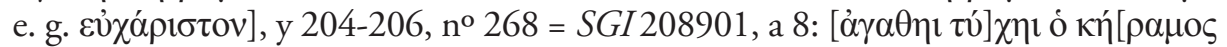

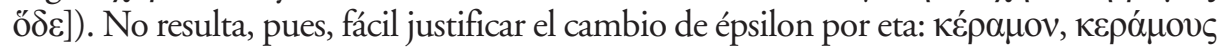
son las formas de acusativo que encontramos en las inscripciones del resto de Grecia. Alternativamente podría quizás leerse, suponiendo la omisión de $\alpha$ después de $\delta \tilde{\omega} \kappa \alpha v$

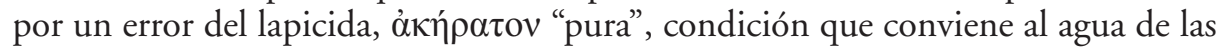
abluciones, como muestra Ilíada 24, 303, Edipo en Colono 471. En Teócrito (Idilio 22,

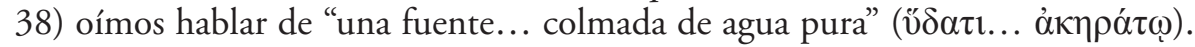

Toda una serie de testimonios nos informa de la importancia del agua en los santuarios para subvenir a las necesidades rituales del templo y de los consultantes. En todo caso, el texto no nos permite decidir si las ofrendas ofrecidas a las divinidades del lugar consistieron, entre otras cosas, en la construcción de una fuente de agua potable, algo muy necesario dadas la temperatura y la calidad ferruginosa 
de las aguas del lugar. Toda una serie de documentos nos atestigua la importancia de contar con una fuente de agua potable en determinados recintos: así, por ejemplo, en Eleusis (I. Eleusis 449), si la restitución es correcta, Trajano dedica una fuente

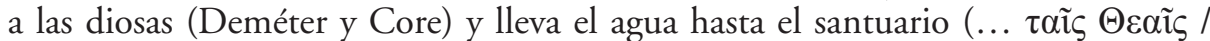

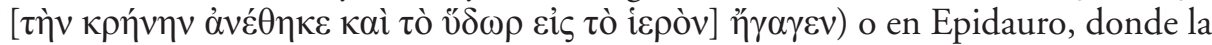
fuente, y el agua de la misma, estaba frecuentemente implicada en el ritual de curación $\left(I G \mathrm{IV}^{2} 1,121 ; 122 ; 126\right)$. Una inscripción procedente del recinto de Asclepio de Atenas ( $I G \mathrm{II}^{2}$ 4464) nos informa de que un tal Sócrates, hijo de Sarapión, constru-

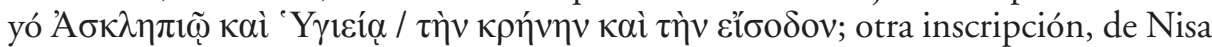
(SGI 261515), recoge la dedicatoria de una fuente y una estatua de Hermes (1. 6:

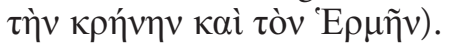

24 Se continúa la relación de ofrendas y sacrificios con la mención de las ofrendas dedicadas a Ártemis: hay otra inscripción votiva de las propias termas de Germisara $(A E 1992,1484=2010,1356=I L D 326: 190$ d. C. $)$ dedicada conjuntamente a las Ninfas, a Diana (Ártemis) y a la fuente: Nymphi[s] sanctis $\mid$ August(is) simul et | tibi, sancta Deana, I fontiq(ue) uestro I retulit sua uolta libens salulti ter refirmatus I aquis Germis(arensibus) (también del mismo lugar, $A E$ 1992, 1479 = ILD 321, inscripción dedicada a Diana). El epíteto habitual de Ártemis cazadora es en los autores clásicos Kvvayóc: así en Sófocles (El. 563) y en Aristófanes (Lys. 1270); la forma de la inscripción es un híbrido de una forma doria con mantenimiento de la $\alpha$ larga

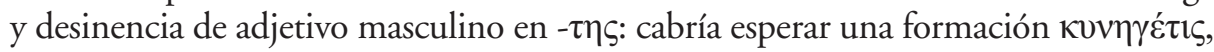
- $1 \delta \mathrm{o} \varsigma$ atestiguada en autores tardíos (cf. Wernicke, $R E$ II.1, 1345, 27 s., donde se citan los testimonios de Corn. ND 34. y Poll. 5, 13). Por lo que se refiere a la epigrafía

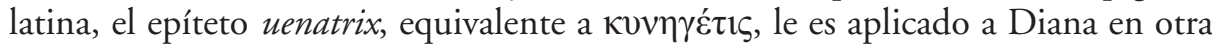
inscripción de Dacia ( $A E$ 1991, 598 = ILD 598: Napoca, $1^{\text {a }}$ mitad del s. III d. C.).

$\kappa \alpha \rho \pi \eta ́ \sigma ı \alpha \delta \tilde{\omega} \rho \alpha$ : son las ofrendas a Ártemis; $\kappa \alpha \rho \pi \eta ́ \sigma ı \alpha$, si es ésta la lectura correcta, es un hapaxque encuentra, sin embargo, alguna explicación como adjetivo derivado de $\kappa \alpha ́ \rho \pi \eta \eta^{15}$, que Hesiquio glosa como $\tau \grave{\alpha} \sigma \pi \varepsilon \dot{\varepsilon} \rho \alpha \tau \alpha$, una especie de tortas con semillas; cabe recordar que a Asclepio y a divinidades paredras se les ofrecían $\pi$ ó $\pi$ ava (cf. Syll. ${ }^{3} 1040=I G \mathrm{II}^{2}$ 4962), unas tortas redondas con semillas. No cabe

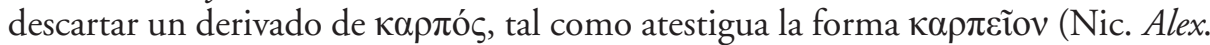
277) con el sentido de 'frutos', que aparece también en plural en un fragmento de Aristófanes (frg. 183 Kassel-Austin, cf. Pellegrino, 2015: 127) con el mismo senti-

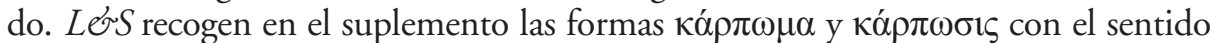
de ofrendas para ser quemadas o frutos. Dos inscripciones de Macedonia $(I G \mathrm{X}, 2,1$,

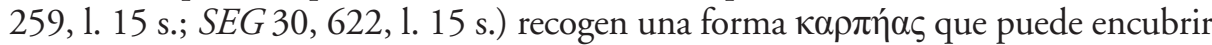
por iotacismo la forma $\kappa \alpha \rho \varepsilon \varepsilon i ́ \alpha$ que designaba el usufructo de los encargados del santuario de las ofrendas ofrecidas. Hay que recordar, sin embargo, la existencia de

\footnotetext{
${ }^{15}$ Formación no recogida, sin embargo, por Chantraine (1933) entre los adjetivos formados con el sufijo - $\sigma 10 \varsigma$.
} 


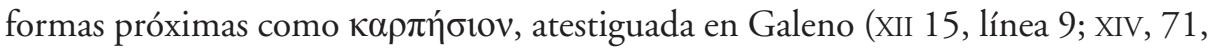

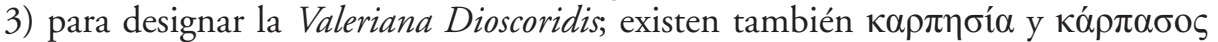
(LひS, s. v.) para designar el lino o el algodón. No obstante, dado el contexto cultual nos inclinamos por ver en la forma un derivado del ya comentado $\kappa \alpha ́ \rho \pi \eta$.

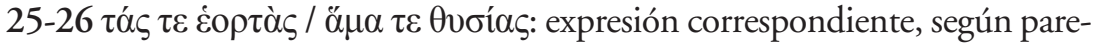
ce, a sollemnia annua de v. 3 .

$\dot{\varepsilon} \pi \alpha v \tilde{\eta} \lambda \theta \alpha \nu$ ó[$[\delta]$ òv $\dot{\varepsilon} \alpha v \tau \tilde{\omega} v$ : hemos comentado ya la desinencia analógica y tardía del aoristo; es notable también el arcaísmo del acusativo interno como muestra

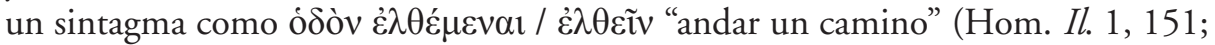
Pl. Prt. 317b -cf. Humbert, 19603: 261). No puede descartarse un calco sintáctico del latín uiam redire "desandar el camino", construcción empleada en la fórmula jurídica redite niam (Cic. Mur. 26) y posteriormente en el lenguaje poético (Verg. Aen. 6, 122: itque reditque uiam...; Stat. Theb. 1, 102: itque reditque uias...; añadase el ire viam de Verg. Aen. 4, 468 y georg. 3, 77 -cf. H.-Sz. 39). El latinismo se vuelve tanto más plausible cuanto la expresión griega غ̇ं $\alpha v \tilde{\eta} \lambda \theta \alpha v$ ó $[\delta] \mathrm{o} v \dot{\varepsilon} \alpha v \tau \tilde{\omega} v$ está lejos de la expresión homérica por la tardía formación verbal.

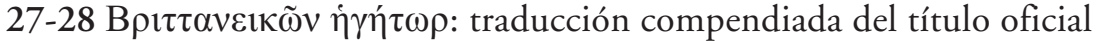
praepositus numeri peditum singularium Britannicianorum (vid. supra).

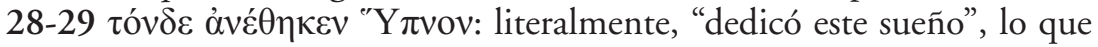
parece que deba entenderse como una estatua de esta divinidad (por ello escribimos, como Piso, "Y $\pi v o v$ con mayúscula). Una inscripción funeraria de Éfeso (IEph 2113

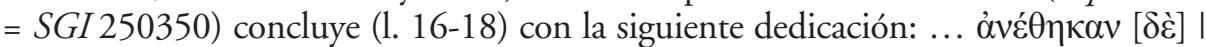

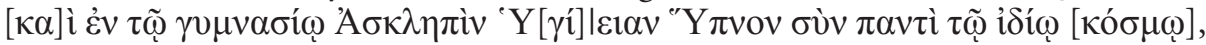
es decir, una estatua de Asclepio acompañado de otras de Hygieia e Hypnos; un epígrafe de Atenas, editado por Peek, 1974: 122, no 1 (= SGI 237365), muestra una dedicatoria de una imagen de Asclepio justificando su aspecto: Eikóv $\alpha \sigma[0 \iota \cup \checkmark-$,

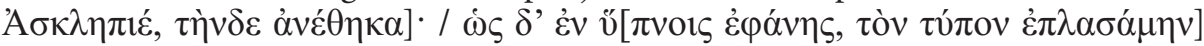
("Te he dedicado, Asclepio, esta estatua; he modelado tu imagen tal como te me apareciste en sueños"). Igualmente una inscripción del famoso Asclepieo de Lebena en Creta (ICret I, XVII, 24) nos informa de la dedicatoria de dos sueños, dos estatuas

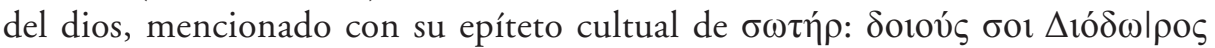

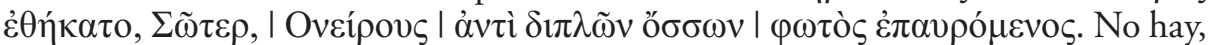
pues, necesidad de alterar la lectura ü $\pi v o v$ (como hace Dana conjeturando ű $\mu \nu$ ov), ya que la ofrenda de imágenes de la divinidad está ampliamente atestiguada. Por otro lado, la atribución de la intervención y actividades del dedicante a la inspiración directa de Asclepio, manifiesta en su epifanía como Hypnos, las vuelve en actos de piedad y de reverencia hacia la divinidad de cuya benevolencia ha traído beneficios para toda la guarnición. De ello se deduce una doble consecuencia: la asistencia a las termas de la guarnición romana y de las milagrosas curaciones logradas es fruto de la voluntad divina; de otro lado, el santuario obtiene el reconocimiento público del agradecimiento del poder militar que asiste regularmente al lugar en busca de tratamientos y curas. La sugerencia de una epifanía del dios al dedicante contribuía, sin duda, a su prestigio personal. "Y $\mathrm{T} v \mathrm{v}$ se nos revela, por tanto, como una palabra clave de este epígrafe, si es correcta nuestra interpretación. Téngase en cuenta, asimismo, la

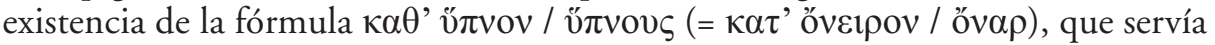


para indicar que la dedicación había estado inducida por una orden divina recibida en sueños: cf. Kühn, 1906: 62-64, y p. ej. IPatmos 3 (sin datación): [A] $\rho \tau \varepsilon \dot{\mu} \mu 1 \delta 1$

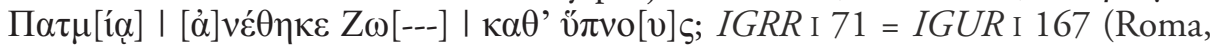

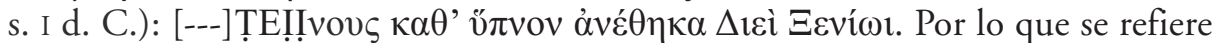
a la epigrafía de las termas de Germisara, hay que traer a colación una dedicación a las Ninfas ex uisu, esto es, inducida también por un sueño: $A E 1992,1486=2010$, 1356 = ILD 328 (201/230 d. C.): Nymphis | sacr(um) | L. Liuius Marlcellus IIuilral(is) col(oniae) pro I filis ex uilsu l(ibens) m(erito).

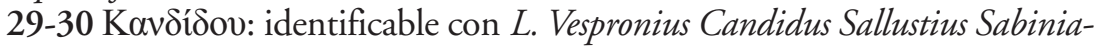
nus, gobernador de las tres Dacias en época de Cómodo: entre los años 183 y 185 (según K. Wachtel y M. Heil, PIR V 439) o entre 183 y 184 (según R. Hanslik, $R E$ VIII A.2, 1716, 31); $\lambda \alpha \mu \pi \rho o ́ \tau \alpha \tau o \zeta$ era el término normalmente empleado para traducir al griego el título clarissimus (uir), ostentado en la época imperial (desde el s. II d. C.) por los miembros del orden senatorial (cf. Lassère, 2005: 643).

32 agens per terr(itorium) Lucanum: uso del verbo ago como tecnicismo militar, con el significado de "versari, castra stationem habere, vigilare" (ThLL I, 1402, 71 ss.); cf. p. ej. Tac. ann. 15, 26, 1: ... legionem quintam, quae per Pontum agens..., así como CIL II $4107=\mathrm{II}^{2} / 14,945$ (Tarraco), 5 ss.: Septimius Acindynus u(ir) c(larissimus) agens per Hispanias...

\section{CONCLUSIONES}

Estamos ante una inscripción singular por su imperfecto bilingüismo, por su complejo propósito y porque excede los límites habituales de una inscripción votiva. Por lo que hace a la lengua o, mejor, lenguas de la inscripción, es evidente la diferencia existente entre el texto latino y el griego. El texto latino presenta una lengua culta y poética: se trata de un extenso carmen en hexámetros dactílicos, en el que es evidente la influencia de los poetas (véanse los muchos loci similes y rasgos del lenguaje poético que hemos señalado en nuestro comentario verso a verso, y recordemos ahora, por ejemplo, la clara adaptación de una cláusula ovidiana en v. 15), si bien hay en él ciertas peculiaridades e imperfecciones habituales en los carmina Latina epigraphica. Las dificultades de interpretación del texto latino se deben, sobre todo, a sus numerosas lagunas, causadas por la rotura del soporte y por la erosión de la superficie epigráfica en algunas líneas; lo que hemos tratado de subsanar mediante nuestras propuestas textuales.

En cambio, el texto griego resulta oscuro y torpe: errores de grafía; léxico dispar, con formas tardías junto con numerosas fórmulas poéticas utilizadas para dar un color y tenor poético y litúrgico; sintaxis elemental, con ausencia de artículos, de partículas y de conjunciones que articulen el texto. Aunque no estamos en disposición de reconstruir el proceso de redacción del texto, la inscripción griega forma parte de un conjunto de textos similares de epígrafes y papiros escritos por una persona con insuficiente competencia lingüística, algo habitual en zonas periféricas como la Dacia de la época, suficientemente romanizada ya pero donde no cabe suponer, dada la ausencia de testimonios, la presencia de una población con dominio del griego. 
En tales casos, como se ha observado ya, la conducta más habitual era el encargo a un romano con alguna cultura griega de un texto latino que se traducía verbum e verbo al griego, con los esperados errores, confusiones y oscuridades que de ello se derivaban (cf. Brixhe, 2001: 677). Aunque en ningún caso determinado estamos seguros de encontrarnos ante un latinismo en este texto, las sospechas de la existencia de latinismos en él son bastantes (téngase en cuenta la omisión casi sistemática del artículo, así como dos usos lingüísticos que hemos comentado ad 1. 20 y 26) como para poder pensar en un procedimiento de traducción como el que acabamos de mencionar. El texto griego se produce, en tal situación, por una razón de prestigio cultural. La población de la zona, aunque no helenizada, estaba en contacto, sin duda, con los colonos griegos del Mar Negro, con Macedonia y con las ciudades griegas de Asia Menor. Tenían conciencia, de un lado, del alto grado de bilingüismo de las clases superiores romanas, así como del prestigio de la lengua y de la cultura griegas en todo el imperio (recordemos que la tendencia helenizante, junto con la tendencia arcaizante, caracterizó la literatura latina de la época: s. II d. C.) y muy especialmente en las provincias orientales. Una inscripción bilingüe aportaba prestigio al dedicante, quien -no olvidemos- era un centurión que había recibido el cargo de comandante (praepositus) de una unidad auxiliar (numerus) de soldados britanos. De otro lado, y dado el tenor del epígrafe, cabe pensar en la intención del dedicante de aproximar los cultos de las termas, y muy especialmente el de Asclepio, al de los grandes Asclepieos griegos y romanos (como parece deducirse de alguna sección de la inscripción) mediante la inclusión de alguna sanatio como las de Epidauro, Atenas, Pérgamo, Lebena y Roma.

\section{REFERENCIAS BIBLIOGRÁFICAS}

$A E=$ L'Année épigraphique, Paris.

$B C H=$ Bulletin de correspondance hellénique, Athènes - Paris.

Bertolazzi, R. (2015): «Notes on the Cult of National Numeri Stationed in the Danubian Provinces», en L. Zerbini (ed.), Culti e religiosità nelle province danubiane. Atti del II Convegno Internazionale Ferrara 20-22 novembre 2013, Bologna, pp. 183-206.

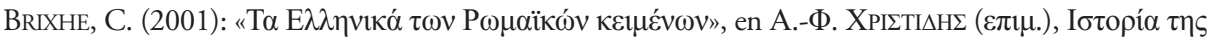

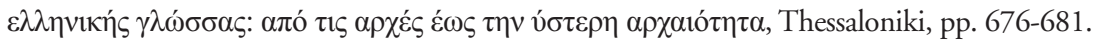

Busch, S. (1999): Versus balnearum. Die antike Dichtung über Bäder und Baden im römischen Reich, Stuttgart - Leipzig.

Chantraine, P. (1933): La formation des noms en grec ancien, Paris.

$C I L=$ Corpus Inscriptionum Latinarum, Berlin (1863 ss.).

$C L E=$ Carmina Latina Epigraphica, Anthologia Latina II 1-2, conlegit F. BÜCHELER, Leipzig (1895-97 [= Stuttgart 1982]); II 3: Supplementum, curavit E. LOMMATZSCH, Leipzig (1926 [= Stuttgart 1982]).

CLEAfr = Carmina Latina Epigraphica Africarum provinciarum post Buechelerianam collectionem editam reperta cognita, collegit, praefatus est, commentariolo instruxit P. CUGUSI adiuvante M. T. Sblendorio Cugusi, Faenza (2014). 
Courtney, E. (1995): Musa lapidaria. A Selection of Latin Verse Inscriptions, Atlanta.

CugusI, P. (1996²): Aspetti letterari dei carmina Latina epigraphica, Bologna.

$D A=$ G. DAREMBERG - E. SAGLIO - E. PotTIER (eds.) (1877-1919): Dictionnaire des antiquités grecques et romaines, Paris.

DANA, D. (2015): «Hymne bilingue aux Nymphes de Germisara», Epigraphica Romana 2015_35_005 [http://www.epigraphica-romana.fr/notice/view? notice=3251].

DeTSCHEW, D. (1957): Die thrakischen Sprachreste, Wien.

EDCS = Epigraphik-Datenbank Clauss / Slaby.

Edelstein, E. J. \& L. (1945): Asclepius. A collection and Interpretation of the Testimonies, Baltimore.

E.-M. = A. ERNOUT - A. MEILLET (1985): Dictionnaire étymologique de la langue latine. Histoire des mots, Paris $\left[=1959^{4}\right.$, con adiciones y correcciones de J. ANDRÉ $]$.

GIL, L. (1969): Therapeia. La medicina popular en el mundo clásico, Madrid.

GUARDUCCI, M. (1987): L'epigrafia greca dalle origini al tardo impero, Roma.

H.-Sz. = J. B. HofmanN - A. SzAnTyR (1965): Lateinische Syntax und Stilistik, München.

Humbert, J. (19603): Syntaxe grecque, Paris.

ICret $=$ M. GUARDUCCI (ed.) (1935-50): Inscriptiones Creticae, I-IV, Roma.

$I D R=$ Inscriptiones Daciae Romanae, Bucarest (1975 ss.).

I. Eleusis = K. Clinton (2005-08): Eleusis. The Inscriptions on Stone. Documents of the Sanctuary of the Goddesses and Public Documents of the Deme, Athens.

IEph = Die Inschriften von Ephesos, Bonn (1979-84).

IG: Inscriptiones Graecae, Berlin (1903 ss.).

$I G R R=$ R. CAGNAT et alii (1901-1927): Inscriptiones Graecae ad res Romanas pertinentes, Paris .

$I G U R=$ L. MORETTI (1968-1990): Inscriptiones Graecae urbis Romae, Roma.

ILD = C. C. PETOleSCU (2005): Inscriptiones Latinae Daciae, Bucarest.

IPatmos = D. F. McCabe - M. A. Plunkett (1985): Patmos inscriptions: Texts and List, Princeton.

Kassel, R. - Austin, C. (1984): Poetae Comici Graeci III. 2, Berlin - New-York.

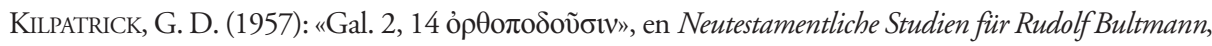
Berlin, pp. 269-274.

K.-St. = R. KÜHNER - C. STEGMANn (1988): Ausführliche Grammatik der lateinischen Sprache. II: Satzlehre, 1-2, Darmstadt $\left[=1976^{5}\right]$.

KüHn, H. (1906): Topica epigrammatum dedicatoriorum Graecorum, Diss. Vratislaviae.

LASSÈre, J. M. (2005): Manuel d'épigraphie romaine, Paris.

LEUMANN = M. LEUMANN $\left(1977^{2}\right)$ : Lateinische Laut- und Formenlehre, München.

Lex. Roscher = W. H. ROSCHER (ed.) (1884-1937): Ausführliches Lexikon der griechischen und römischen Mythologie, Leipzig.

L\&S: H. G. LidDelL - R. SCOTT - H. S. Jones (1996): A Greek-English Lexicon, Oxford [= 1940²].

Lunelli, A. (cur.) (19883): La lingua poetica latina (saggi di W. Kroll, H. H. JANSSEN, M. LeumANN), Bologna.

MARINé BigorRa, S. (1952): Inscripciones hispanas en verso, Barcelona - Madrid. 
Mitford, T. B. (1980): The nymphaeum of Kafizin. The inscribed pottery, Berlin - New York.

Moreno Soldevilla, R. (2006): Martial, Book IV. A Commentary, Leiden - Boston.

Nau, F. (1907-13): «Histoire des solitaires égyptiens», Revue de l'Orient Chrétien 12-18.

Отто, А. (1890): Die Sprichwörter und sprichwörtlichen Redensarten der Römer, Leipzig.

Palmer, L. R. (1980): The Greek Language, London - Boston.

PECS = R. STILLWELL - W. L. MACDONALD (eds.) (1976): The Princeton Encyclopedia of Classical Sites, Princeton.

PeeK, W. (1974): «Epigramme von der Agora», en D. Bradeen - M. F. McGregor (eds.), Phoros. Tribute to Benjamin Dean Meritt, Locust Valley, N. Y., pp. 121-131.

Pellegrino, M. (2015): Aristofane. Frammenti, Prensa Multimedia, Lecce.

Petolescu, C. C. (2017): «Cronica epigrafică a României (XXXVI, 2016)», SCIVA 68: 191-211.

$P I R^{2}=$ Prosopographia Imperii Romani saec. I. II. III, Berlin (1933-2015) [2a ed.].

PIsO, I. (2015): «Ein Gebet für die Nymphen aus Germisara», Acta Musei Napocensis 52/1: 47-68.

$R E=$ A. PAuly - G. WissoWA - W. KROLL (eds.) (1894-1980): Paulys Realencyclopädie der classischen Altertumswissenschaft, Stuttgart - München.

RoberTs, C. H. (1939): "A note on Galatians II 14», The Journal of Theological Studies 40: 55-56.

Rотн, H. (1935): Untersuchungen über die lateinischen Weihgedichte auf Stein, Diss. Gießen.

Rusu, A. - Pescaru, E. (1993): «Germisara daco-romaine», en D. Alicu - H. Boegli (eds.), Politique édilitaire dans les provinces de l'Empire Romain, II ime $-I V^{i m e}$ siècles aprés J. C. Actes du Colloque roumano-suisse, Deva 21-26 Octobre 1991, Cluj-Napoca, pp. 201-215.

$S G I=$ Searchable Greek Inscriptions. A Scholarship in Progress, The Packard Humanities Institute, Cornell University, Ohio State University [epigraphy.packhum.org].

Syll. $^{3}=$ W. DitTENBERGER (1915-24): Sylloge inscriptionum Graecarum, 4 vols., Leipzig.

$T h L L=$ Thesaurus linguae Latinae, Leipzig (1900 ss.).

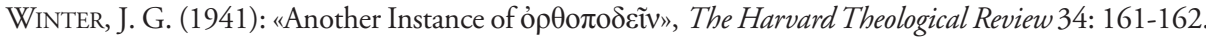

ZARKer = J. W. Zarker (1958): Studies in the Carmina Latina Epigraphica, Diss. Princeton, pp. 134-280. 